\title{
Exploratory study regarding how cultural perspectives can influence the perceptions of project success in Brazilian companies
}

\author{
Pamela Adelino Ramos ${ }^{\text {**, }}$ Caroline Maria de Miranda Mota ${ }^{\text {*** }}$ \\ aniversidade Federal de Pernambuco, Recife, PE, Brasil \\ *pamela.ppgep@gmail.com, **mota.cmm@gmail.com
}

\begin{abstract}
Due to globalization and dynamic business environment, teams in companies are multicultural; as a result, culture may become an important aspect to be considered. The majority of articles regarding projects include factors of success and failure, but only a few embrace cultural perspectives. To provide more insight into the effects of cultural perspectives, this paper presents findings from an exploratory study that investigated how Brazilian information technology companies perceive project success and failure, and then makes inferences regarding the cultural factors. Interviews and questionnaires were applied, and the results provide insights for understanding how cultural factors may influence the project success perceptions. As the primary results, contributions regarding cultural perceptions are offered and related to different dimensions with a view to exploring the cultural aspects as determinant factors of success in a project management environment.
\end{abstract}

Keywords

Project. Project management. Culture. Success and failure.

\section{Introduction}

The recognition of project success factors can be used to analyze the reasons for success and failure in projects. Since the 1960s, theoretical and empirical studies have been undertaken to indentify these factors (Pheng \& Chuan, 2006). But, according to Müller \& Jugdev (2012) there is no clear definition of project success. Projects represent the deep relationship of today's business environment with the different factors that can influence these projects. Many articles discuss about critical success factors but few of them address culture as a factor of influence (Eberlein, 2008). Over the last decades, several scholars developed frameworks for measuring dimensions of culture (House et al., 2004; Smith, 2006). Hofstede $(1980,2001)$ proposed dimensions for classifying cultures across the world. This cross-cultural study triggered interest in cultural analysis in several research studies. For example, according to Trompenaars \&t Woolliams (2003), many suggested models seek to embrace culture, but they can be criticized for underestimating the difficulty involved in organizations or because they tend to disregard the current situation.

The focus of this study is to examine factors of success and failure as observed by the Brazilian IT companies surveyed with a view to making inferences about cultural perspectives on management projects so as to judge if cultural aspects are important to obtain success. Considerations of success and failure factors in descriptive analysis enabled to investigate the relationship of these factors with cultural aspects in the organizations studied to be investigated.

Success and failure in projects have been attributed to factors such as type of management, project requirements, management practices, or to the inappropriate management of areas of a project (Kandelousi et al., 2011; Haughey, 2010) but have ignored the cultural and human aspects of project performance. There is a need to prospect beyond 
such factors to find new answers to explain why there are different perceptions of success and failure factors in projects.

Project environments are characterized by levels of complexity and uncertainty that create difficulties in identifying project success or failure factors (Chipulu et al., 2014). Several studies on projects concluded that the triad of factors (cost, quality and time) continues to be the main cause of failure and success in projects around the world but a perception of culture is essential to discover if other kinds of factors bring their influence to bear on success or failure. According to Yang et al. (2011, p. 265), “[...] project success in terms of schedule, cost, qualify and stakeholder satisfaction can be achieved with a stronger team communication, collaboration and cohesiveness".

According to Miller et al. (2000) culture can affect a project in several ways, for example, due to globalization, cultural differences can increase team heterogeneity because each person brings his or her ideologies, beliefs and attitudes that if well managed lead to heterogeneous teams performing better than homogeneous ones.

This paper is organized into the following sections: This section 1 presented a short introduction to success and cultural factors and the focus of work. Section 2 gives a brief review of the literature about how projects are conceived of; success and failure factors; success in information technology (IT) projects and cultural aspects in organizations. Section 3 explains the methodology of the research. This section describes how the sample was chosen, which research questions were asked, the type of survey conducted and how many steps were taken. Section 4 is about results and is divided into two parts to aid a better understanding of these. In 4.1, responses from the interviews are descriptively analyzed. $\ln 4.2$, responses from the questionnaires are analyzed and related to the four dimensions of Hofstede's work. Section 5 draws some conclusions about achievements, the contribution of this study and its limitations. The findings are explained and justified.

\section{Brief review of the literature}

The Project Management Institute (2008) defines a project as a temporary endeavor undertaken to create a unique product, service or result. A project is normally a periodic activity with a non-recurring development, characterized by a logical sequence of events and intended to achieve a clear and defined objective. It is driven by people who respect the parameters of time, cost, resources, and quality.
Figure 1 presents the main objectives of project management. Each project is different yet includes time, cost and performance to achieve organizational goals. Organizations often have many concurrent projects that simultaneously generate competition for resources. To solve this problem, there is a need for agreement between all the interested parties and for the priorities of the organization to be defined.

Success factors in projects are widely studied. Among these studies is one by Cooke-Davies (2002), who structured a list of 12 factors of success that are implemented by many national and multinational organizations, namely: the adequacy of company-wide education on the concepts of risk management; the maturity of an organization's process for assigning ownership of risks; the adequacy with which a visible risk register is maintained; the adequacy of ensuring the risk management plan is kept up-to-date; the adequacy of documentation of organizational responsibilities for the project; keeping the length of a project (or project stage duration) as far below 3 years as possible ( 1 year is better); allowing changes to the scope only by following a mature process for changing the scope; maintaining the integrity of the baseline for measuring performance; the need to have an effective process for evaluating the delivery of benefits and management that involves the mutual co-operation of project managers and line managers; portfolio and program management practices that allow the enterprise to resource fully a suite of projects that are thoughtfully and dynamically matched to corporate strategy and business objectives; a suite of projects, program and portfolio metrics that provides direct "line of sight" feedback on current project performance, and anticipated future success, so that project, portfolio and corporate decisions can

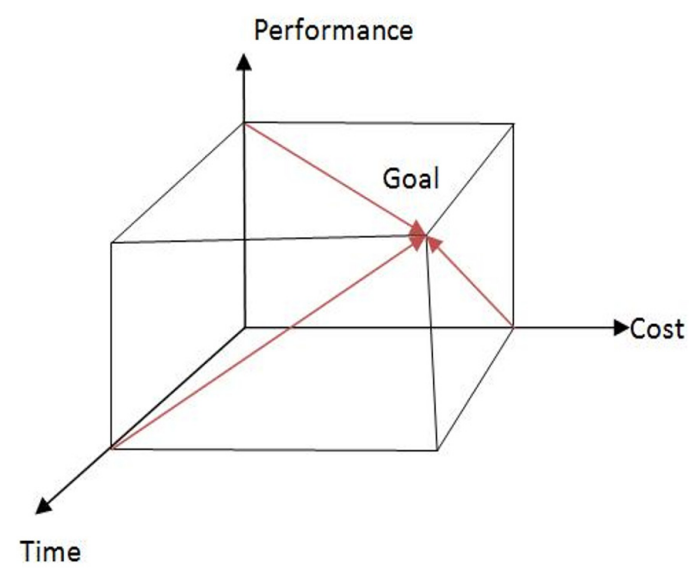

Figure 1. Performance, time, cost and goal of the project. Source: Atkinson (1999). 
be aligned; an effective means of "learning from experience" on projects, in a way that encourages people to learn and to embed that learning into a process of continuous improvement in project management process and practices.

However, as Cooke-Davies (2002) reports in his article, the human factor as a determinant of the extent of project success is omitted. This omission is justified for two reasons: the research was focused on what people do and not on the quality of their interactions and decision-making and secondly, because there was no separation of human factors and process factors, the human factor being implicit.

According to Repiso et al. (2007), to achieve success in managing an Information Technology project, what must be taken into account is that there are certain peculiarities in IT projects that make them different from other types of project. For example, they are characterized by high complexity and high chances of project failure. IT projects are poorly defined, involve numerous iterations and contain a greater degree of novelty.

Another example of peculiarities in IT projects is their life cycles. According to The Project Management Institute (2008), the life cycle of a project is a set of stages that can vary in number from four to nine phases. Stewart (2008) proposed the process for managing an IT project life cycle. Each stage consists of a step by step approach that must be followed so that each phase evolves to the next, thus causing the project to be constantly selected, implemented and evaluated. Moreover, it is necessary to understand the life cycle of IT projects to find out which factors contribute to success and in which stage perceptions of success are most perceived.

According to Thomas \& Fernandéz (2008), the criteria that are commonly used to define success may be grouped into three categories: the success of project management, of technical matters and of the business, as shown in Table 1. These criteria were investigated by using an exploratory study in 36 companies to measure the information technology project.

Likewise, according to Schwalbe (2014, p. 51), "[...] just as an organization's structure affects its ability to manage projects, so does its culture". The IT department, as well as, its projects, may have a different organizational culture from that of other departments and some cultures make it easier to manage projects.

Müller \& Turner (2010) consider the orientation towards giving due considerations to project participants and stakeholders as fundamental to obtaining success from a project. Managing IT projects requires different knowledge and skills because different projects have different natures, so it is necessary to define in which culture dimension the project environment is located. According to Hofstede $(1980 ; 2001)$, culture consists of four dimensions: power-distance; avoidance of uncertainty; individualist versus collectivist; and masculinity.

- Power-distance: Indicates the degree to which society accepts the fact that power in institutions and organizations is distributed unequally;

- Uncertainty Avoidance: Indicates the degree to which society feels threatened by uncertain and ambiguous situations, an uncertainty avoidance approach therefore includes trying to avoid people worrying about job stability, rules being formalized, and violations of ideas and behaviors not being tolerated.

- Individualist versus Collectivist: Individualism implies taking care of things that are directly linked to the a person's sense of feeling whereas collectivism is characterized by concern for the group;

- Masculinity: Tries to explain the scale of masculine values in society, thereby separating male from female values.

There is a need to study the cultural context to try to understand the behavior in organizations that can lead failure or success in their projects. Miller et al. (2000) affirms that the more diverse a project can be, the more innovative and creative the teams will be because multiple points of view greatly enhance how projects are developed. Groups can influence each other and the relationship with bosses and other employees builds a strong structure of trust and cooperation.

Table 1 . Criteria used by the project participants to judge the success.

\begin{tabular}{lccc}
\hline \multicolumn{1}{c}{ Success Criteria } & $\begin{array}{c}\text { Project } \\
\text { Management }\end{array}$ & Technical & Business \\
\hline Time & $\mathrm{x}$ & & \\
Cost & $\mathrm{x}$ & & \\
Sponsor satisfaction & $\mathrm{x}$ & & \\
Group satisfaction & $\mathrm{x}$ & & \\
Client satisfaction & $\mathrm{x}$ & $\mathrm{x}$ & \\
Stakeholder satisfaction & $\mathrm{x}$ & $\mathrm{x}$ & \\
System implementation & & $\mathrm{x}$ & \\
Requirements & & $\mathrm{x}$ & \\
System quality & & $\mathrm{x}$ & \\
System utility & & $\mathrm{x}$ & \\
Business & & & $\mathrm{x}$ \\
Goals achievement & & & $\mathrm{x}$ \\
Benefits & & & $\mathrm{x}$ \\
\hline So: & & & \\
\hline
\end{tabular}

Source: Thomas \&t Fernandéz (2008). 


\section{Methodology}

The method applied in this research is an exploratory survey and the sampling is non-probabilistic intentional, which means the researcher chooses certain types of elements to belong to the sample. In this case, these are the people directly related to the company's information technology projects. The criterion used was to find companies in the area of IT with projects that had been structured, organized and developed, including companies of different sizes: 59\% were large, 22\% medium, 6\% small and 13\% micro.

The research methodology was based on an exploratory study regarding perceptions of project success and failure (Ojiako et al., 2012). This article explores the results from Brazilian companies through the use of an initial questionnaire made with collaboration between some international universities.

The study had two steps. Firstly, interviews were held with 10 project managers from ten IT companies in Brazil; a primarily qualitative research was used, through observations in loco, in order to get insights about managers' perceptions.

The second step of our study was based on a questionnaire applied in $33 \mathrm{IT}$ companies, to understand some cultural contexts, which may be related to the interview. The questionnaire was applied to different practitioners involved in IT projects, such as project managers, analysts and directors.

The interview consisted of four open questions that enabled the respondent to build his/her answer freely; the four themes of the interviews were designed to identify the determinants of success and failure; grading success; the perception of success and the stakeholder's perception.

The first question considers which factors are most relevant for the respondents and the answers are shown in Table 2. The second question is about how respondents ranked success and failure. The third question regards the conception of success and failure throughout the life cycle of the project. And the fourth question asked if different stakeholders have different perceptions about the project. The answers to questions 2, 3 and 4 are in Table 3.

The questionnaire consisted of 40 statements using a 5-point Likert scale, an ordinal scale category ranking, with values of 1 to 5 where 1 means strongly agree, 2 means agree, 3 means neither agree nor disagree, 4 means disagree and 5 means strongly disagree. This enabled the responses to be compared for the purpose of data analysis. The statements used in this work are given in Table 4.

According to Pearse (2011, p. 160), “[...] there has been much debate on what should be regarded as an optimal number of response categories". The number of points that should be used by researchers remains unclear (Weathers et al., 2005). It did not take long for the scale published by Likert (1932) to become popular. There were many reasons for this. For example, it stood apart from the type of psychometrics, generalizations, and the complexity of alternative ranges (Cummins \& Gullone, 2000). The application of 5-point scale in this study is justified by its having been used in prior studies in this research area and adaptations made to it in past studies (Ojiako et al., 2012). The number of classifications that humans

Table 2. Evaluation of interviews regarding factors of success and failure.

\begin{tabular}{|c|c|c|}
\hline Organizations & Factors that define Success & Factors that define Failure \\
\hline Organization 1 & Customer expectation; Scope; Time; Risk & $\begin{array}{l}\text { The relationship between the factors of failure are inversely } \\
\text { proportional to that determine success }\end{array}$ \\
\hline Organization 2 & $\begin{array}{l}\text { Requirements Cost, Quality, Time and Scope; People and } \\
\text { appropriate tools and Monitoring Project }\end{array}$ & $\begin{array}{l}\text { Lack of communication; lack of experience of people and } \\
\text { lack of Knowledge of market }\end{array}$ \\
\hline Organization 3 & Communication, Focus, Persistence and Cooperation Team & $\begin{array}{l}\text { Lack of clarity of objectives; Uncommitted Team; Leadership } \\
\text { and Lost Time Market }\end{array}$ \\
\hline Organization 4 & $\begin{array}{l}\text { Profitability, Customer Expectations, Achievement and } \\
\text { Improvement Society }\end{array}$ & Loss; Customer Dissatisfaction; Bring harm to society \\
\hline Organization 5 & $\begin{array}{l}\text { Good project planning; complete the planned; Flexibility to } \\
\text { change; Teamwork }\end{array}$ & $\begin{array}{l}\text { The relationship between the factors of failure are inversely } \\
\text { proportional to that determine success }\end{array}$ \\
\hline Organization 6 & Clarity in goals, planning, competent staff & $\begin{array}{l}\text { The relationship between the factors of failure are inversely } \\
\text { proportional to that determine success }\end{array}$ \\
\hline Organization 7 & Customer expectation, Cost, Time and Quality & $\begin{array}{l}\text { Not achieving success factors; Defining Project Scope and } \\
\text { External Dependencies }\end{array}$ \\
\hline Organization 8 & Organization requirements; schedule and cost & $\begin{array}{l}\text { The relationship between the factors of failure are inversely } \\
\text { proportional to that determine success }\end{array}$ \\
\hline Organization 9 & $\begin{array}{l}\text { Communication; Defining scope; Customer Relationship and } \\
\text { Cost / Quality / Schedule }\end{array}$ & $\begin{array}{l}\text { The relationship between the factors of failure are inversely } \\
\text { proportional to that determine success }\end{array}$ \\
\hline Organization 10 & $\begin{array}{l}\text { Qualified professionals; project purpose and Enabling } \\
\text { Environment }\end{array}$ & $\begin{array}{l}\text { Unqualified professionals; Rework and lack of knowing what } \\
\text { to do }\end{array}$ \\
\hline
\end{tabular}


Table 3. Evaluation of interviews regarding the classification of success and failure and conflict among stakeholders.

\begin{tabular}{llll}
\hline Organizations & \multicolumn{1}{c}{ Rating of Success and Failure } & \multicolumn{1}{c}{$\begin{array}{c}\text { Conception of Success or } \\
\text { Failure }\end{array}$} & Stakeholders' conflict \\
\hline Organization 1 & Three Levels: Extremely Successful; Successful; Total Failure & Conclusion & Yes \\
Organization 2 & Two levels: Success; Failure & Planning & Yes \\
Organization 3 & Three Levels: Extremely Successful; Successful; Total Failure & lmplementation & Yes \\
Organization 4 & Three Levels: Extremely Successful; Successful; Total Failure & All the lifecycle & Yes \\
Organization 5 & Four levels: Extremely Successful; Successful; Failure; Total Failure & Planning & Yes \\
Organization 6 & Three Levels: Extremely Successful; Successful; Total Failure & Conclusion & Yes \\
Organization 7 & Two levels: Success; Failure & Planning & Yes \\
Organization 8 & Four Levels: Extremely Successful; Successful; Failure; Total Failure & Planning and lmplementation & Yes \\
Organization 9 & Three Levels: Extremely Successful; Successful; Total Failure & All the lifecycle & Yes \\
Organization 10 & Three levels: Extremely Successful; Failure; Total Failure & Planning & Yes \\
\hline Source: The authors. & & &
\end{tabular}

Table 4. Correlations.

\begin{tabular}{|c|c|c|c|}
\hline Affirmatives & Affirmatives & Coefficients & $\begin{array}{l}\text { Strength of } \\
\text { association }\end{array}$ \\
\hline 1 enjoy taking risk & 1 will always cooperate to keep group harmony & 0.43 & $\begin{array}{l}\text { Positive and } \\
\text { moderate }\end{array}$ \\
\hline 1 will always cooperate to keep group harmony & $\begin{array}{l}\text { When working on a project, } 1 \text { would rather work } \\
\text { as a group member than as an individual }\end{array}$ & 0.45 & $\begin{array}{l}\text { Positive and } \\
\text { moderate }\end{array}$ \\
\hline $\begin{array}{l}\text { It is important that people conform to company } \\
\text { norms in order to reach to company goals }\end{array}$ & $\begin{array}{l}\text { lt is important for managers to make all } \\
\text { decisions }\end{array}$ & 0.41 & $\begin{array}{l}\text { Positive and } \\
\text { moderate }\end{array}$ \\
\hline $\begin{array}{l}\text { If an individual thinks in a different way to perform } \\
\text { a task, that person should be encouraged to do it } \\
\text { that way. }\end{array}$ & Power and wealth are evil & 0.41 & $\begin{array}{l}\text { Positive and } \\
\text { moderate }\end{array}$ \\
\hline Power and wealth are evil & $\begin{array}{l}\text { 1t is important for managers to make all } \\
\text { decisions }\end{array}$ & 0.56 & $\begin{array}{l}\text { Positive and } \\
\text { moderate }\end{array}$ \\
\hline
\end{tabular}

Source: The authors.

can best hold in their working memory is between two and seven. More points can cause confusion and difficulty in decision making. In this study, the authors wished to obtain answers in which agreement and disagreement were expressed more precisely. Initially, a test was performed with postgraduate students as the process for validating the questionnaire.

Cronbach's coefficient alpha was calculated to estimate the reliability of the questionnaires; the alpha value found in this study was 0.88 . According to Streiner (2003) the minimum acceptable value for the reliability of a questionnaire is 0.70 . Usually, the preference is for alpha values are between 0.80 and 0.90 .

Finally, an investigation was made of the cultural perspectives that can be measured by using correlation values and relating these to the four dimensions of Hofstede's work. The data analysis was developed using statistical method tools. Spearman's correlation analysis was used to relate some affirmatives of the questionnaire while descriptive analysis was used to associate these affirmatives with the dimensions of Hosftede's work.

\section{Results}

This research was conducted in IT companies so as to understand what factors are linked to the failure or success of IT projects. In the following sections, descriptive and exploratory analyses of the data collected from these companies are given. First the interviews will be analyzed and then the questionnaires.

\subsection{Analysis of the interviews}

The interview questions were about what factors are related to success and failure and how they are ranked and related; whether project success and failure can be graded; whether the perceptions of success and failure change with time and when they are formed; and whether stakeholders in projects have different perceptions about the project and how they manage this type of conflict.

Firstly, interviews were conducted so as thereafter to analyze the perception of the determinants of success and failure in IT companies. Table 2 shows 
the factors that determine success and failure in IT projects according to the interviewees.

As can be seen in Table 2 each respondent ranked and ordered the factors that he/she thinks important if a project is to be successful. According to the respondents, the factors most remembered as determinants of success comply with the requirements of schedule, cost, quality and scope. Most respondents said that not satisfying the factors that determine success are factors that determine failure. In other words, the relationship between the factors of failure is inversely proportional to those that determine success; this interpretation was deduced after collecting the respondents' opinions. It may be noted that none of the respondents judged the culture as a determinant of project development.

As can be seen in Table 3, most respondents ranked success and failure in three levels. This means that there is a fuzzy concept between success and failure that allows sorting on many different levels, which could, for example, be an extremely successful project, a success, a failure and a total failure, for example. Regarding the conception of success and failure throughout the life cycle of the project, the majority of respondents, $60.0 \%$, agreed that at least three levels of classification could be defined. This shows that there is a clear identification of which type of project tends to be successful.

With respect to dealing with possible conflicts between the perceptions of stakeholders, all of the respondents replied positively. In other words, all of them consider that the management and negotiation of the parties involved in the project is important. Therefore, as many as possible of their requirements should be seen to have been met.

This initial study was to examine the situation of some IT Brazilian companies and their projects using interviews and questionnaires. The first part of the study investigated what the main factors of success and failure observed by managers would be and concludes that they still consider the most frequently-used factors (cost, quality and time) to be the main factors that influence project performance. Failure is considered to be non-fulfilment of these factors. This leads to presuming that this sample has a traditional and conservative behavior with regard to other factors that might influence projects. Another issue regarding how success and failure are rated was that it could be proved that there is no understanding about how many levels of success and failure there are nor about how the conception of success and failure can be sub-divided in a way that satisfies all respondents. Moreover, it was observed that there is conflict between stakeholders regarding decision making and this is reflected in poor communication and bad management. There is a need for good conflict management to avoid this kind of problem. The assessment of success and failure projects depends on individual stakeholders' view of this and can vary according to the period of the life cycle project. For example, if a project did not fulfill the objectives of cost and time but achieved other results, it can be considered a success by one or more users and a failure by the others (Cleland \&t Ireland, 2007). It was found that most of the stakeholders considered human and personal factors (differences between stakeholders, 82\%; differences between private interests, $88 \%$ and conflicting visions about solving a problem $88 \%$ ) as important influencing factors in judging success or failure in projects.

\subsection{Analysis of the questionnaires}

In the second part of the research, questionnaires were applied to elucidate the current situation regarding the cultural aspect of $\mathrm{IT}$ projects by analyzing some statements to verify the respondent's individual views and their attitudes and to relate these to the four dimensions of Hofstede's work. It is possible to relate questions from questionnaires with the dimensions of culture considering how different perceptions of the context of a project can make influence in organizational factors and personal attitudes at work, as can be seen in Table 4 .

In order to discover the determinants of success and failure in IT projects in Brazilian companies, an exploratory analysis was performed using the Spearman's correlation analysis. However, the information gathered relates only to the sample and may not be extended to the population. The variation of the correlation coefficient varies according to the strength of association and some statements and the respective correlation coefficients obtained are shown in Table 4.

We now turn to giving a descriptive analysis of correlated affirmatives shown in Table 4 and this will include taking note of the relation between the affirmatives and also between Hofstede's four cultural dimensions. Figure 2 shows that $71.42 \%$ of the respondents like to take risks, while only $7.14 \%$ do not. With regard to cooperation and group harmony, most respondents (92.85\%) affirm that they are available to cooperate so as to maintain group harmony, as most (64.28\%) prefer to work as a member of a group member rather than individually on their own.

This reflects a pattern of behavior that fits with the Collectivist dimension of Hofstede (1980). An interest in group cooperation and teamwork can be discerned 
in this sample. But even if there is a propensity to taking risks, these respondents respect the work environment and their relationships, and therefore they will not normally insist on such risks being taken whether this affect the project environment.

Figure 3 shows that most respondents, 93.93\% strongly agree and slightly agree about the importance of people complying with the company's norms because the same objectives can be achieved but, on the other hand, with respect to decision making it is clear that most respondents consider that employees should participate in decision-making, a fact confirmed by the significant disagreement about the managers making all decisions, $72.72 \%$.

It can be seen in this small sample, that the respondents agreed with the importance of reaching

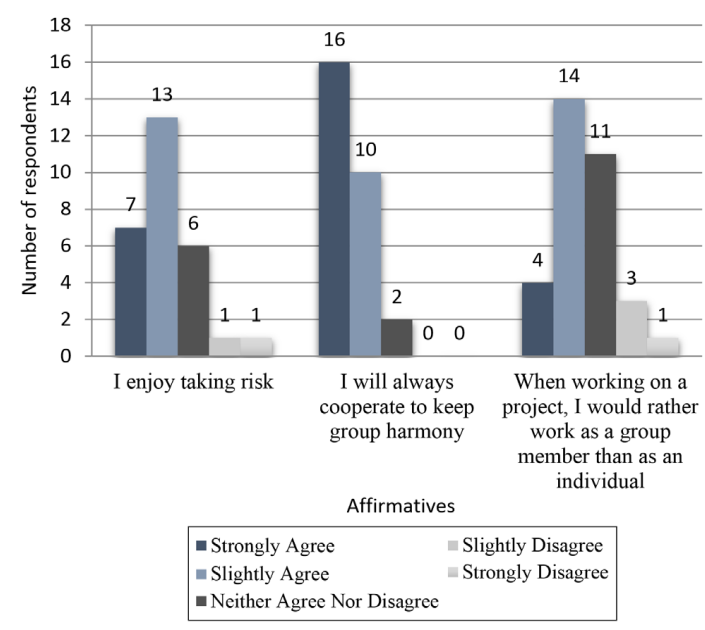

Figure 2. Cooperation and group harmony. Source: the authors.

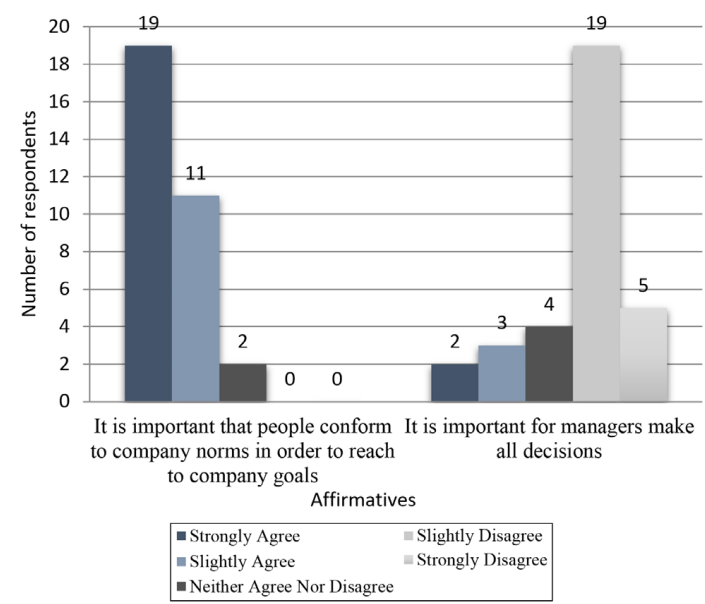

Figure 3. Compliance with norms. Source: the authors. company goals, but disagree with managers making all decisions. This reflects the disagreement with how power should be distributed in institutions referenced by Hofstede's work in the Power-distance dimension.

In Figure 4, the majority of respondents disagreed with all affirmatives. $57.57 \%$ of the respondents disagreed with the question about being encouraged to do some activity by themselves. This may be associated with the Uncertainty Avoidance dimension of Hosftede's work, because the respondents try to keep away from uncertain and ambiguous situations, avoid them and worry about their job stability.

The majority, $81.82 \%$ disagreed that power and wealth are evil and $72.72 \%$ also disagreed that managers should make all decisions. These two statements are connected to the Power-distance dimension of Hosftede's work because the respondents believe that power is not bad but does not deal adequately with inequalities in the decision-making process.

Most respondents are male, $85 \%$, so it is concluded that the answers of the questionnaires are largely given by male managers, but the answers do not exactly reflect this dimension only because the majority is male. With respect to the Masculinity dimension of Hofstede's work, this sample was more oriented towards femininity because it tends to emphasize parameters such as good relationships and avoiding conflicts. This gender dimension shows that this sample, according to Hofstede (2001), displays a preference for cooperation and consensus orientation, which reflects the concern about relationships and conflict management.

Moreover, some correlations can be seen between other affirmatives in relation to group cooperation, trust and recognition. The correlation between

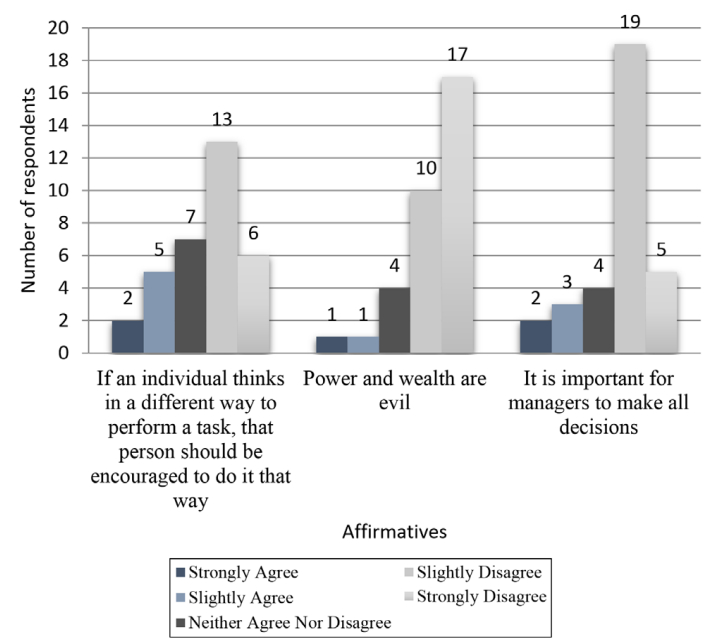

Figure 4. Organizational attitudes. Source: the authors. 
cooperation and trust in people, for example is about the following affirmatives: "l always cooperate to keep group harmony" and " 1 like to trust and cooperate with other people". The intention was to see if there is cooperation so as to maintain the organizational harmony and to analyze the degree of cooperation and trust in organizations. But in this small sample, it can be observed that these two affirmatives are not strongly correlated: the coefficient value is 0.34996 , but this does not demonstrate that there is not a relationship between these affirmatives.

Likewise, Figure 5 shows the correlation between recognition of an individual and recognition of a job well done. The affirmatives are: "It is very important to me to receive recognition for my work" and "It is important that 1 receive individual recognition at work". The intention was to ascertain if recognition of work well done is something relevant in people's lives and to ascertain the importance of individual recognition at work. Once again what is observed that these two affirmatives are not strongly correlated: the coefficient value is 0.34467 , so there is little correlation between job recognition and individual recognition.

The correlation between the size of an organization and satisfaction with the salary and job can be verified. The affirmatives are: "1 would rather work for a small company than a large one" and "the most important things in my career are a good salary and having a job that 1 do well and like". The intention was to judge if the size of a company matters and the importance of remuneration and function of the respondents. It can be observed that these two affirmatives are not strongly correlated: -0.19 , so, there is no correlation between the size of a company and satisfaction with the salary and job.

It is important to notice that that these three last correlations had low coefficient values whereas the expectation would be they would have a moderate or high correlation coefficient. As to the correlation between cooperation and trust: a strong correlation was expected between variables to understand that those who like to cooperate usually place their trust in other people, as their work will be something collective. With regard to the correlation between individual and job recognition: a strong correlation was expected between the variables of job recognition and individual recognition because they usually go in the same positive or negative direction. Similarly, as to the correlation between organization size and satisfaction: a strong correlation was expected between the size of a company, salary and job satisfaction in the belief that in a large organization there is greater mobilization regarding the search for motivational

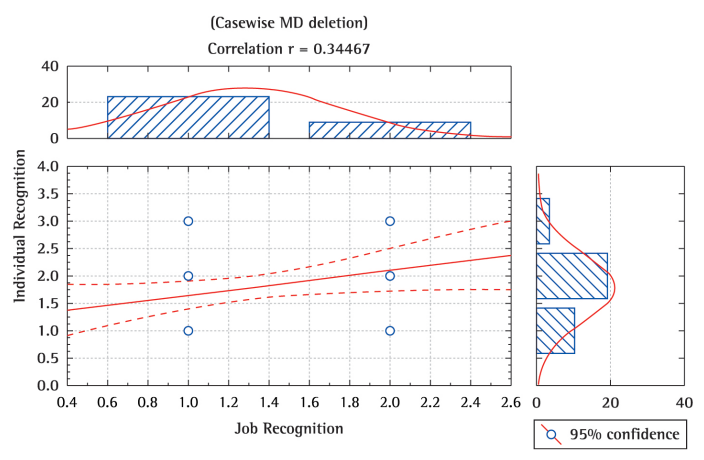

Figure 5. Correlation between individual and job recognition. Source: the authors.

aspects and these are generally related to having a good salary and job satisfaction.

As a result of this exploratory study, it can be seen that the contributions regarding cultural perceptions observed may help companies to understand how people and projects should be managed and that cultural differences when observed and understood enable us to work in greater depth with the values of the different actors in the project management environment. Moving in this direction, future studies should be conducted which involve other variables regarding management, leadership, behavior and characteristics of projects so as to seek improvements and excellence in management.

\section{Conclusions}

Based on a content analysis of interviews and questionnaires, it is concluded that, in general, this study achieved the proposed goals, despite some limitations of time, distance and access to respondents. Information technology companies are becoming ever more present and important for national economies and the global economy. Researches on issues involving how to make improvements in this sector are of great importance and have a substantial contribution to make; this study seeks to make such a contribution.

This study has explored the local situation of IT projects, albeit with a small sample and the difficulties arising from the time, cost and research dimensions. The sample may not be large enough to be able to prove the correlations that are usually expected and more variables are needed to prove the construct presented. But the interviews and questionnaires used in this research will contribute to exploring the perception of the effect of culture as a determinant of success and failure in Brazilian IS/IT projects and therefore is vital for developing future research. 
Interviews were used to gain insights into the different individual views of the respondents. This enabled some inferences to be made from their responses to the questionnaires. These are given in the results section. So, the responses from the interviews are the data sources that enrich the understanding of the purpose of the research.

In the second part, the study of cultural perspective was conducted in order to investigate some behaviors using the respondents' answers about cultural context in their jobs. First of all, it was noticed that cultural factors which may influence project performance are still being neglected by the managers and organizations.

According to Hofstede (1980), it can be seen that this sample exhibits characteristics of a sense of collectivity, as shown in Figure 2, and these are essential for good working relationships. Regarding the Power-Distance dimension, it was observed that there is compliance with rules and norms but there is a struggle for a more equal distribution of decision--making. As to Uncertainty Avoidance, the sample seeks to avoid problems and uncertainties that lead to ambiguous situations for fear of making mistakes. Even though the majority of the sample consisted of males, one can observe that values such as good relationships and avoiding conflicts are present and according to Hofstede's work, the sample has femininity parameters.

The most remarkable result to emerge from the data is that cultural factors were disregarded as one important agent that can make influence on success or failure in projects. This partially explains why communication has been considered as a determinant factor since communication is linked to how an organization interacts and how the organizational culture of a company is established.

It can be clearly concluded that, in all of the companies where interviews and questionnaires were conducted, cultural aspects have not been considered as one determinant factor of success and failure because these companies are still attached to traditional concepts and achievements of success and failure. Through the study of cultural aspects presented in results, a classification in each of Hofstede's dimension could be traced that can help these organizations to improve their environment and lead to better management of projects.

\section{References}

Atkinson, R. (1999). Project management: cost, time and quality, two best guesses and a phenomenon, its time to accept other success criteria. International Journal of Project Management, 17(6), 337-342. http://dx.doi.org/10.1016/ S0263-7863(98)00069-6.
Chipulu, M., Ojiako, U., Gardiner, P., Williams, T., Mota, C., Maguire, S., Shou, Y., Stamati, T., \& Marshall, A. (2014). Exploring the impact of cultural values on project performance: The effects of cultural values, age and gender on the perceived importance of project success/failure factors. International Journal of Operations \& Production Management, 34(3), 364-389. http://dx.doi.org/10.1108/1JOPM-04-2012-0156.

Cleland, D. 1., \&t Ireland, L. R. (2007). Project management: strategic design and implementation (5th ed.) New York: McGraw-Hill.

Cooke-Davies, T. (2002). The real success factors on projects. International Journal of Project Management, 20(3), 185190. http://dx.doi.org/10.1016/S0263-7863(01)00067-9.

Cummins, R. A., \&t Gullone, E. (2000). Why we should not use 5-point Likert scales: the case for subjective quality of life measurement. In Proceedings of the Second International Conference on Quality of Life in Cities (pp. 74-93), Singapore.

Eberlein, M. (2008). Culture as a critical success factor for project management. Journal of Information Technology Management, 19(3), 27-43.

Haughey, D. (2010). How to recruit an IT project manager (pp. 1-4). Project Smart. Retrieved in 10 January 2014, from http://www.projectsmart.co.uk

Hofstede, G. (1980). Motivation, leadership, and organization: do American theories apply abroad? Organizational Dynamics, 9, 42-63. http://dx.doi.org/10.1016/0090-2616(80)90013-3.

Hofstede, G. (2001). Culture's consequences: comparing values, behaviors, institutions, and organizations across nations (2nd ed.). Thousand Oaks: Sage Publications.

House, R. J., Hanges, P. J., Javidan, M., Dorfman, P. W., \& Gupta, V. (2004). Culture, leadership, and organizations: the Globe study of 62 societies. Thousand Oaks: Sage Publications.

Kandelousi, N. Sh., Ooi, J., \&t Abdollahi, A. (2011). Key success factors for managing projects. World Academy of Science, Engineering and Technology, 5, 11-24.

Likert, R. (1932). A technique for the measurement of attitudes. Archives de Psychologie, 140, 44-53.

Miller, M. D., Fields, R., Kumar, A., \&t Ortiz, R. (2000). Leadership and Organizational Vision In Managing a Multiethnic and Multicultural Project Team. Journal of Management Engineering, 16(6), 18-22. http://dx.doi.org/10.1061/ (ASCE)0742-597X(2000) 16:6(18).

Müller, R., \& Jugdev, K. (2012). Critical success factors in projects, Pinto, Slevin, and Prescott: the elucidation of project success. International Journal of Project Management, 5(4), 757-775. http://dx.doi.org/10.1108/17538371211269040.

Müller, R., \&t Turner, R. (2010). Leadership competency profiles of successful project managers. International Journal of Project Management, 28(5), 433-448. http://dx.doi. org/10.1016/j.jproman.2009.09.003.

Ojiako, U., Chipulu, M., Gardiner, P., Williams, T., \& Mota, C. (2012). Cultural imperatives in perceptions of project success and failure (Chapter 3-6). Feltham: Project Management Institute.

Pearse, N. (2011). Deciding on the scale granularity of response categories of likert type scales: the case of a 21-point scalethe case of a 21-point scale. Electronic Journal of Business Research Methods, 9(2), 159-171.

Pheng, L. S., \&t Chuan, Q. T. (2006). Environmental factors and work performance of project managers in the construction 
industry. International Journal of Project Management, 24(1), 24-37. http://dx.doi.org/10.1016/j.jproman.2005.06.001.

Project Management Institute - PMl. (2008). A guide to the Project Management Body of Knowledge: PMBOK. (4th ed). Pensylvania.

Repiso, L. R., Setchi, R., \&t Salmeron, J. L. (2007). Modelling IT projects success: Emerging methodologies reviewed. Technovation, 27(10), 582-594. http://dx.doi.org/10.1016/j. technovation.2006.12.006.

Schwalbe, K. (2014). Information technology project management (7th ed.) Boston.

Smith, P. B. (2006). When Elephants fight, the grass gets trampled: the GLOBE and Hofstede projects. Journal of International Business Studies, 37(6), 915-921. http:// dx.doi.org/10.1057/palgrave.jibs.8400235.

Stewart, R. A. (2008). A framework for the life cycle management of information technology projects: ProjectlT. International Journal of Project Management, 26(2), 203-212. http:// dx.doi.org/10.1016/j.ijproman.2007.05.013.
Streiner, D. L. (2003). Being inconsistent about consistency: when coefficient alpha does and doesn't matter. Journal of Personality Assessment, 80(3), 217-222. http://dx.doi. org/10.1207/S15327752JPA8003_01. PMid:12763696.

Thomas, G., \& Fernandéz, W. (2008). Success in IT Projects: A matter of definition? International Journal of Project Management, 26(7), 733-742. http://dx.doi.org/10.1016/j. ijproman.2008.06.003.

Trompenaars, F., \&t Woolliams, P. (2003). A new framework for managing change across cultures. Journal of Change Management, 3(4), 361-375. http://dx.doi. org/10.1080/714023847.

Weathers, D., Sharma, S., \&t Niedrich, R. W. (2005). The impact of the number of scale points, dispositional factors, and the status quo heuristic on scale reliability and response accuracy. Journal of Business Research, 58(11), 1516-1524. http://dx.doi.org/10.1016/j.jbusres.2004.08.002.

Yang, L., Huang, C., \& Wu, K. (2011). The association among project manager's leadership style, teamwork and project success. International Journal of Project Management, 29(3), 258-267. http://dx.doi.org/10.1016/j.jproman.2010.03.006. 